\title{
Traditional birth attendants lack basic information on HIV and safe delivery practices in rural Mysore, India
}

\author{
Purnima Madhivanan ${ }^{1 *}$, Bhavana N Kumar ${ }^{1}$, Paul Adamson², Karl Krupp ${ }^{1}$
}

\begin{abstract}
Background: There is little research on HIV awareness and practices of traditional birth attendants (TBA) in India. This study investigated knowledge and attitudes among rural TBA in Karnataka as part of a project examining how traditional birth attendants could be integrated into prevention-of-mother-to-child transmission of HIV (PMTCT) programs in India.

Methods: A cross-sectional survey was conducted between March 2008 and January 2009 among TBA in 144 villages in Mysore Taluk, Karnataka. Following informed consent, TBA underwent an interviewer-administered questionnaire in the local language of Kannada on practices and knowledge around birthing and HIV/PMTCT.

Results: Of the 417 TBA surveyed, the median age was 52 years and $96 \%$ were Hindus. A majority $(324,77.7 \%)$ had no formal schooling, 88 (21.1\%) had up to 7 years and $5(1 \%)$ had more than 7 yrs of education. Only 51 of the 417 TBA (12\%) reported hearing about HIV/AIDS. Of those who had heard about HIV/AIDS, only 36 (72\%) correctly reported that the virus could be spread from mother to child; 37 (74\%) identified unprotected sex as a mode of transmission; and 26 (51\%) correctly said healthy looking people could spread HIV. Just 22 (44\%) knew that infected mothers could lower the risk of transmitting the virus to their infants. An overwhelming majority of TBA $(401,96.2 \%)$ did not provide antenatal care to their clients. Over half $(254,61 \%)$ said they would refer the woman to a hospital if she bled before delivery, and only $53(13 \%)$ felt referral was necessary if excessive bleeding occurred after birth.

Conclusions: Traditional birth attendants will continue to play an important role in maternal child health in India for the foreseeable future. This study demonstrates that a majority of TBA lack basic information about HIV/AIDS and safe delivery practices. Given the ongoing shortage of skilled birth attendance in rural areas, more studies are needed to examine whether TBA should be trained and integrated into PMTCT and maternal child health programs in India.
\end{abstract}

\section{Background}

Worldwide, it is estimated that there are more than 60 million non-institutional births each year with the vast majority being attended by traditional birth attendants (TBA) [1]. In most developing countries in South Asia, less than half of pregnant women receive trained medical assistance during their delivery[2,3]. While shockingly high, this figure still masks an even greater underlying inequality between urban and rural areas

\footnotetext{
* Correspondence: pmadhivanan2@gmail.com

${ }^{1}$ Public Health Research Institute of India, 89/B, 2nd Cross, 2nd Main,

Yadavgiri, Mysore, 570020, India

Full list of author information is available at the end of the article
}

where most of the population resides. In developing countries, rural mothers are $40 \%$ less likely to be attended by skilled health personnel compared with their urban counterparts[2].

With almost $60 \%$ of births occurring at home[4], India faces a variety of challenges in providing high quality maternal child healthcare. Currently, the estimated maternal mortality ratio (MMR) at 450 per 100,000 live births, casts doubt upon the country's ability to reach its Millennium Development Goal of 109 maternal deaths per 100,000 live births by 2015 [1]. The country has also made only slow progress in expanding access to antiretrovirals for prevention of mother-to-child transmission

\section{Ciomed Central}


of HIV (PMTCT). Each year only about $20 \%$ of the estimated 50,000 HIV positive pregnant women receive prophylaxis to prevent transmission of HIV to their infant [5].

There is growing evidence from Africa and other parts of the world showing that TBA may be able to play an important role in improving maternal child outcomes and preventing HIV. Greenwood et al, in their randomized control trial on TBA training in Gambia, demonstrated a $62 \%$ reduction in maternal mortality. Their study also showed a significant increase in maternal tetanus immunization rates, and maternal antenatal attendance among mothers delivering with trained TBA [6]. Jokhio and colleagues, in their large cluster randomized intervention study on prevention of perinatal mortality in Pakistan, reported a $20 \%$ reduction in perinatal death when TBA were trained and provided with disposable delivery kits[7]. Perez et al, in a large feasibility study of TBA willingness to participate in HIV prevention programs in Zimbabwe, found $75 \%$ acceptability among TBA to participate in HIV prevention activities such as accompanying new-borns to closest health centre to receive medication (15\%) and assisting health centers in documenting ANC-PMTCT services [8]. Another study in Tanzania showed that women receiving HIV advice from a trained and motivated TBA were three times more likely to accept an HIV test and also had a three-fold increased chance of receiving Nevirapine for prevention of mother-to-child transmission of HIV[9].

There are few recent studies on the birthing practices of TBA in India, and none investigating knowledge and attitudes about HIV. Stella Mulder and Karen TrollopeKumar in studies from different parts of India reported a number of customary practices among TBA. Mulder observed that many attendants were replacing traditional practices for treating the cord stump with ash or dung [10] with more modern remedies such as antiseptic powder. Similarly, Trollope-Kumar observed that many TBA she studied also administered both allopathic and herbal medicines[11]. Other common TBA practices described in these studies included: providing advice on diet and activity $[10,11]$, disposing of the placenta through burial $[10,11]$, delivering women in a supine or crouching position, sprinkling water on the child immediately after birth, and wiping the baby with coconut or castor oil followed by a warm soap bath[10]. Mulder also noted that TBA appeared to have low knowledge regarding many life-threatening complications including excessive bleeding, prolonged labor, and vaginal tears[10].

This study investigated practices and knowledge about birthing and HIV/PMTCT among active TBA attending births in rural areas of Mysore Taluk in the south Indian state of Karnataka.

\section{Methods}

\section{Study Site}

Karnataka state with an MMR of 221 per 100,000 live births has the highest rate of maternal death among South Indian States[12]. It has also been identified as one of the 6 high HIV prevalence states in the country. Rates of infection vary substantially across the state's 27 districts with an average of just under $1 \%$ of antenatal clinic attendees being infected with HIV[13]. Mysore District is located in the southern part of the state bounded by Mandya district to the northeast, Chamrajanagar district to the southeast, Kerala state to the south, Kodagu district to the west, and Hassan district to the north. The district has an area of $6,854 \mathrm{~km}^{2}$ and a population of $2,641,027$, of which about half $(49 \%)$ are females[14]. Approximately $62.8 \%$ of the population live in rural areas. Overall, the literacy rate is $63.5 \%$. Hindus constitute $87.4 \%$ of the population, Muslims $8.9 \%$, and Christians, Buddhists and other religious groups about 3.7\%. Kannada and Urdu are the dominant languages in this area.

\section{Data collection}

Between August and November 2009, 511 TBA were screened and 417 enrolled in a descriptive cross-sectional survey. To be eligible, a potential participant had to be able to speak Kannada or $U r d u$; understand and give informed consent; and have delivered a minimum of 10 babies in the previous year. The survey was conducted in 144 villages located ten kilometers or more outside of Mysore City since active TBA in Mysore District are typically found in rural areas with poor access to medical care. TBA were identified through key-informant interviews with village elders, community health workers, and recently delivered mothers registered with government health workers. In addition, participating TBA were asked to refer any other birth attendants they knew of in their local area. Three Masters degree-level graduates in Social Work or Psychology were selected as interviewers. All interviewers were trained for four weeks in issues around relationship building, privacy and confidentiality, and methods for administering questionnaires in a standardized, non-judgmental fashion. After undergoing an informed consent process, eligible TBA answered a structured face-to-face interview in Kannada in a private setting at their home or place of work. The study was approved by the Vikram Hospital Independent Ethics Committee.

\section{Statistical analysis}

Data were analyzed using Stata 10.1 (Stata Corporation, College Station, TX). Descriptive statistical methods were used to provide a general profile of the study 
population. Analyses were conducted using Pearson chisquared or Fisher-exact tests for categorical variables and $t$-tests for comparison of continuous variables.

\section{Results}

\section{Demographics}

Of the 511 TBA screened, 428 (83.7\%) were found eligible for the study. Reasons for non-eligibility included having delivered less than 10 babies in the previous year or being unable to give informed consent. Of the 428 eligible women, 417 (97.4\%) agreed to be interviewed. The median age of study participants was 52 years (range: $26-80$ years) with 77 (18\%) aged 40 years or less, 138 (33\%) between 41-54 years, and 202 (48\%) over 55 years of age. A large majority $(324,77.7 \%)$ had no formal education, 88 (21\%) had between one and seven years and five (1.2\%) had more than seven years of education. Among these participants, 415 (99.5\%) were Hindus and two $(0.48 \%)$ were Muslim. None of the participants reported full time employment as a TBA.

\section{Knowledge, Attitudes and Beliefs about HIV/AIDS}

Only 51 of the 417 (12.3\%) TBA reported hearing about HIV/AIDS. Among those, 25 (49\%) wrongly believed that only 'sick looking' people could spread infection, and 21 (42\%) thought HIV could be transmitted through touching or hugging. Additionally, 32 (64\%) reported that HIV could be spread by mosquitoes and 11 (21.6\%) were not aware that the virus could be transmitted through blood or blood products. When asked about vertical transmission of HIV, 14 (28\%) did not know that HIV could be spread from mother to child and 28 (56\%) were unaware that infected mothers could deliver healthy infants. When TBA were asked what precautions they took to protect themselves against HIV, 39 (76\%) said they avoided attending births for women they suspected were HIV-infected, 3 (6\%) reported wearing rubber gloves during deliveries, 2 (4\%) said they rubbed oil on their hands prior to carrying out procedures, $3(6 \%)$ reported taking herbal remedies before deliveries, 2 (4\%) cleaned all surfaces after each procedure, and 1 (2\%) reported using sterilized blades and instruments.

\section{TBA Birthing Practices \\ Antepartum Practices}

A large majority $(401,96.2 \%)$ of TBA reported not providing antenatal care for the woman prior to the onset of labor contractions. About 372 TBA (89\%) advised women to use special postures when seated, 354 (85\%) advised special postures for sleep, 282 (68\%) prescribed special foods and diets, 255 (61\%) told women to massage their abdomen with special oils, and 182 (43\%) suggested exercise. When participants were asked how abortions were carried out in their village, 88 (21\%) reported consumption of raw papaya, 61 (14.6\%) reported consumption of heat producing foods, and 318 (76\%) reported they didn't know.

\section{Intrapartum Practices}

Almost all TBA $(404,96.9 \%)$ reported telling their clients to contact them only at the onset of fast painful contractions. Among the remainder, 23 (6\%) advised waiting until the water breaks, and $10(2.4 \%)$ told their clients to notify them once the child's head crowned. The supine position was the most commonly reported delivery posture $(228,54.7 \%)$, followed by squatting $(140,33.6 \%)$, sitting $(105,25.2 \%)$ and kneeling $(43$, $10.3 \%)$. When asked what tools were used during deliveries, almost all (98\%) reported using a blade, $25(6 \%)$ a scissors, $2(0.5 \%)$ forceps, and $2(0.5 \%)$ a suction bulb. Just over half $(183,51.9 \%)$ reported sterilizing their equipment prior to a delivery. When TBA were asked whether they would ever refer women to a medical center, $70 \%$ said they would if the baby was stuck, if a mother had excessive bleeding before delivery (60.9\%) and if the baby came out the wrong way (56.8\%). Other reasons reported for hospital referrals were: if the umbilical cord came out before the baby (37.9\%), if there was excessive bleeding following birth $(12.7 \%)$, if the placenta was stuck (11.2\%), and if the umbilical cord was wrapped around the baby's head (4.6\%) (Table 1).

\section{Postpartum Practices}

If the baby did not cry immediately after delivery, 126 (32.6\%) TBA reported splashing the baby with cold water; 115 (27.6\%) blew in the baby's ear; 108 (25.9\%) massaged the baby's back, hands and feet; 82 (19.7\%) flicked the baby's feet, 65 (15.6\%) held the baby upside down and 22 (5.3\%) would refer the mother and infant to a medical center. Less than a third of participants $(113,27.1 \%)$ said they advised clients to breastfeed immediately after delivery. About half, 186 (44.6\%) told women that they could breastfeed after several hours, while $99(23.7 \%)$ advised waiting for 24 hours and 19 (4.6\%) specified other periods. Most (77.7\%) reported telling clients that colostrum was good for the baby, but $91(21.8 \%)$ advised against it.

\section{Discussion}

This study shows that knowledge about HIV/AIDS is extremely low among TBA living in rural areas of Mysore Taluk. An overwhelming majority (88\%) of surveyed birth attendants had not even heard of HIV/ AIDS, a surprising finding given that the epidemic in India is more than two decades old. This is in stark contrast to high levels of knowledge found by the government of India among the general population in HIV sentinel surveillance surveys. The 2006 National Behavioral Surveillance Survey showed 75 percent of people living in rural areas were aware of HIV/AIDS[15]. Even 
Table 1 Birthing practices of traditional birth attendants in Mysore Taluk, India ( $\mathrm{N}=417)$

Characteristic
Would you consider this a high-risk pregnancy
Age $<17 \&>35$ yrs
First pregnancy or $>5$ times pregnant
Past h/o spontaneous abortion
Past h/o blood pressure
Past h/o caesarian section
Past h/o postpartum hemorrhage
Stillbirth during last delivery
Abnormal presentation of fetus
Mother's height $<1.45$ m
Fetus stops moving or unable to hear the baby
Twins
Do you advise any of the following treatments
Special food and diet
Enema
Exercise
Massage with oil on stomach
Special posture to sit
Special posture to sleep
Medicines
Pushing out the abdomen during the pain

When do you advise your clients to get you when they are ready to deliver

Breaking of bag of waters

Fast painful contractions

Head is coming out

What is the most common posture for delivering a woman in labor

$$
\begin{aligned}
& \text { Seated } \\
& \text { Squatting } \\
& \text { Laying down } \\
& \text { Kneeling }
\end{aligned}
$$

What would you do if there is excessive bleeding before delivery

Refer to medical center

Do nothing, will have normal delivery

Don't know

What would you do if there is excessive bleeding after delivery

Wait until 'bad blood' has passed

Refer to medical center

What would you do: After the baby is delivered, the placenta becomes stuck inside the woman or it does not come out right away

Massage the uterus

Manually clear the placenta by hand

Induce vomiting by stuffing hair into mouth in order to $65 \quad 15.6$ expel placenta

Induce vomiting by sticking hand into mouth in order to expel placenta

Drink castor oil

Refer to medical center

Total

N (\%)

$210 \quad 50.4$

$163 \quad 39.1$

$208 \quad 49.9$

$245 \quad 58.8$

$267 \quad 64.0$

$178 \quad 42.7$

$228 \quad 54.7$

$288 \quad 69.1$

$171 \quad 41.0$

$288 \quad 69.1$

$228 \quad 54.7$

$282 \quad 67.6$

$\begin{array}{ll}13 & 3.1\end{array}$

18243.6

$\begin{array}{ll}255 & 61.2\end{array}$

$\begin{array}{ll}372 & 89.2\end{array}$

$354 \quad 84.9$

$\begin{array}{ll}78 & 18.7\end{array}$

$191 \quad 45.8$

$23 \quad 5.5$

40496.9

$10 \quad 2.4$

$105 \quad 25.2$

$140 \quad 33.6$

$228 \quad 54.7$

$43 \quad 10.3$

$254 \quad 60.9$

$6 \quad 1.44$

$19 \quad 4.56$

41499.3

$\begin{array}{ll}53 & 12.7\end{array}$

$18 \quad 4.3$

10.2

$47 \quad 11.2$
Table 1 Birthing practices of traditional birth attendants in Mysore Taluk, India ( $\mathbf{N}=417)$ (Continued)

Don't know

$11 \quad 2.6$

What would you do if:

Umbilical cord comes out of the woman before the baby

Deliver baby normally $\quad 15 \quad 3.6$

$\begin{array}{lll}\text { Manually push the cord back inside the woman } & 54 & 12.9\end{array}$

Rotate the baby's position inside the mother $\quad 11 \quad 2.6$

$\begin{array}{llll}\text { Refer to medical center } & 158 & 37.9\end{array}$

Don't know $156 \quad 37.4$

Refuse to answer $\quad 15 \quad 3.6$

Umbilical cord is wrapped around the baby's head

Leave the cord until the baby is delivered $\quad 10424.9$

Loosen the cord around the baby's neck 23957.3

Tie and cut the cord after the shoulders come through $\quad \begin{array}{lll}15 & 3.6\end{array}$ the pelvis

Refer to medical center $\quad 19 \quad 4.6$

Don't know $\quad 15 \quad 3.6$

$\begin{array}{lll}\text { Refuse to answer } & 3 & 0.72\end{array}$

Baby is stuck inside the mother

Change the position of the mother $\quad \begin{array}{ll}3 & 3.1\end{array}$

Refer to the medical center $\quad 29270.0$

Don't know $12 \quad 12.88$

Refused to answer $\quad 5 \quad 1.2$

Baby comes out the wrong way

Deliver the baby normally $\quad 123 \quad 29.5$

Refer to medical center $\quad 237 \quad 56.8$

Don't know $\quad 39 \quad 9.35$

$\begin{array}{lll}\text { Refuse to answer } & 3 & 0.72\end{array}$

Mother gets a fever, feels dizzy or becomes pale

$\begin{array}{lll}\text { Give mother water to drink } & 92 & 22.1\end{array}$

Refer to medical center $\quad 194 \quad 46.5$

Don't know $\quad 389.1$

$\begin{array}{lll}\text { Refuse to answer } & 1 & 0.24\end{array}$

There are cuts and tears in the woman's vaginal wall after birth

Wash with soap and water $\quad 93 \quad 22.3$

Apply turmeric with oil $\quad 11 \quad 2.6$

Don't know $133 \quad 31.9$

$\begin{array}{lll}\text { Refused to answer } & 9 & 2.2\end{array}$

A newborn does not cry

Blow in the baby's ear $\quad 115 \quad 27.6$

Splash baby with cold water $\quad 126 \quad 32.2$

Massage baby's back, feet or hands $\quad 108 \quad 25.9$

Hold baby with legs upward $\quad 65 \quad 15.6$

$\begin{array}{llll}\text { Flick the baby's hands or feet } & 82 & 19.7\end{array}$

Refer to medical center $\quad 22 \quad 5.3$

the small number of TBA in our study, who had knowledge about HIV demonstrated poor understanding about how the virus was transmitted. Additionally, less than half of those were aware of the potential for preventing vertical transmission of HIV. Finally, 39 of the 
51 TBA (76\%) who had said they had heard of HIV/ AIDS, expressed unwillingness to attend the births of HIV-infected mothers.

The level of knowledge about safe birthing practices was also low among TBA. Considering that obstetrical hemorrhage and sepsis are still the leading cause of maternal death in India[16], it is not surprising that the study found only $13 \%$ of TBA referred mothers experiencing excessive bleeding following birth to a medical center, and that only about half (51.9\%) sterilized equipment prior to deliveries. Other 'unsafe' procedures still practiced among TBA included sucking secretions out of a baby's mouth and nose with their mouth, applying cow dung, ghee (clarified butter) and other preparations on the umbilical cord, and inducing vomiting by stuffing hair in a woman's throat to stimulate contractions of the uterus to clear the placenta. Even more concerning, TBA appeared to have low levels of awareness about when clients should be referred to a hospital. A small number of TBA (4.6\%) said they would refer a mother to a medical center if the umbilical cord was wrapped around the baby's head, and just over half (56.8\%) would refer the mother if the baby was coming out the wrong way. Most TBA but not all (70\%) would refer the woman if the baby was stuck inside the birth canal.

While knowledge deficits on both HIV and birthing practices among TBA appear large, they underline a continuing dilemma for countries like India where more than $60 \%$ of the population lives in rural areas[17]. While the Government of India has made substantial investments in increasing rural healthcare through its National Rural Health Mission, access to skilled birth attendance is still an unrealized goal for much of the population. Integrating TBA in the rural health system may be a viable short-term solution for lowering maternal and infant mortality in rural areas with limited access to medical care. Additionally, as some studies in Africa have shown $[8,18]$, TBA could contribute to HIV prevention efforts, particularly those focused on motherto-child transmission of HIV. Studies in India have already demonstrated that training TBA can improve newborn care[19], increase uptake of maternal health services[20], and reduce neonatal mortality[21]. The difficulties of training TBA should not be underestimated however. Many have low levels of literacy and some may not be interested in further training. Attention must be given to making instruction relevant to the local cultural milieu in which TBA practice and germane to the realities of rural birth attendance. Furthermore, any effort to integrate TBA must be harmonized with national health policies and the existing priorities of the National Rural Health Mission. Given all these challenges, training TBA may still be India's best hope for reaching Millennium Development Goal 5 by 2015.
This study has several limitations. First, it was carried out among rural TBA living in Mysore Taluk and may not be representative of TBA in other areas of India. In addition, it was impossible to verify how large a practice each TBA had since this was self reported and might have been subject to recall and information bias. Second, respondents' accounts of events around pregnancy and childbirth may be subject to recall and information bias. It is likely that the TBA may have underreported some practices leading to a conservative estimate of our findings because of social desirability bias. Finally, it is likely that some of the questions were not answered by the respondents, as they may have not understood the vocabulary or terminology in spite of the fact that the questions were from formative research conducted prior to this study among TBA in the region.

\section{Conclusion}

Traditional birth attendants will continue to play an important role in maternal child health in India for the foreseeable future. This study demonstrates that a majority of TBA lack basic information about HIV/ AIDS and safe delivery practices. Given the ongoing shortage of skilled birth attendance in rural areas, more studies are needed to examine whether TBA should be trained and integrated into PMTCT and maternal child health programs in India.

\section{List of Abbreviations}

AIDS: Acquired Immuno Deficiency Syndrome; HIV: Human

Immunodeficiency Virus; MMR: Maternal Mortality Ratio; PMTCT: Prevention of Mother to Child Transmission of HIV; TBA: Traditional Birth Attendants; UNICEF: United Nations Children's Fund; WHO: World Health Organization.

\section{Competing interests}

The authors declare that they have no competing interests.

\section{Authors' contributions}

PM and KK were involved in the conception and design of the study. BNK and PA were responsible for acquisition of data and PM analyzed the data. PM and KK drafted the article and all authors (PM, BNK, PA, KK) participated in interpreting the data and critically revising the manuscript for important intellectual content. All authors read and approved the final version of the manuscript to be published.

\section{Acknowledgements}

For their generous assistance on this project, the authors would like to thank the Project Kisalaya team for all their efforts in data collection and all TBA in the study for their participation. We would like to express our appreciation to Zonta, Wyoming for their generous donations of birthing kits. In addition, the authors would like to express their gratitude to Dr Arthur Amman, president of Global Strategies for HIV Prevention for advising on this project and critically reviewing the manuscript for content and language.

Funding/Support: This work was supported by an Elizabeth Glaser Pediatric AIDS Foundation International Leadership Award to Purnima Madhivanan. Role of the Sponsor: Elizabeth Glaser Pediatric AIDS Foundation had no role in the study design, conduct, collection, management, analysis, or interpretation of the data, or preparation, review, or approval of the manuscript. 


\section{Author details}

${ }^{1}$ Public Health Research Institute of India, 89/B, 2nd Cross, 2nd Main, Yadavgiri, Mysore, 570020, India. ${ }^{2}$ San Francisco Department of Public Health 1360 Mission Street, Suite 401, San Francisco, CA 94103, USA

Received: 22 March 2010 Accepted: 22 September 2010

Published: 22 September 2010

\section{References}

1. UNICEF: State of the World's Children 2009: Maternal and Newborn Health. New York. 2009

2. Childinfo: Monitoring the situation of women and children. [http://www. childinfo.org/delivery_care.html].

3. McClure EM, Wright LL, Goldenberg RL, Goudar SS, Parida SN, Jehan I, Tshefu A, Chomba E, Althabe F, Garces A, et al: The global network: a prospective study of stillbirths in developing countries. Am J Obstet Gynecol 2007, 197(3):247, e241-245.

4. Mavalankar D, Vora K, Prakasamma M: Achieving Millennium Development Goal 5: is India serious? Bulletin of the World Health Organization 2008, 86(4):243-243A.

5. WHO: PMTCT strategic vision 2010-2015: preventing mother-to-child transmission of HIV to reach the UNGASS and Millennium Development Goals. Geneva: World Health Organization 2010

6. Greenwood AM, Bradley AK, Byass P, Greenwood BM, Snow RW, Bennett S, Hatib-N'Jie AB: Evaluation of a primary health care programme in The Gambia. I. The impact of trained traditional birth attendants on the outcome of pregnancy. The Journal of tropical medicine and hygiene 1990, 93(1):58-66.

7. Jokhio $A H$, Winter $H R$, Cheng KK: An intervention involving traditional birth attendants and perinatal and maternal mortality in Pakistan. The New England journal of medicine 2005, 352(20):2091-2099.

8. Perez F, Aung KD, Ndoro T, Engelsmann B, Dabis F: Participation of traditional birth attendants in prevention of mother-to-child transmission of HIV services in two rural districts in Zimbabwe: a feasibility study. BMC public health 2008, 8:401.

9. Msaky H, Kironde S, Shuma J, Nzima M, Mlay V, Reeler A: Scaling the frontier: traditional birth attendant involvement in PMTCT service delivery in Hai and Kilombero districts of Tanzania. abstract no.: ThPeE8084. International Conference on AIDS 2004; Bangkok, Thailand 2004.

10. Mulder S: Midwifery in rural India: a study of traditional birth attendants in Tamil Nadu, India. Aust Coll Midwives Inc J 1995, 8(1):24-30.

11. Trollope-Kumar K: The Traditional Birth Attendant in Garhwal, India: Towards a Culturally Relevant Training Program. Canadian Journal of Midwifery Research and Practice 2002.

12. Special Bulletin on Maternal Mortality in India 2004-06. [http:// censusindia.gov.in/Vital_Statistics/SRS_Bulletins/MMR-Bulletin-April-2009.pdf].

13. Karnataka State Profile. [http://newdelhi.usembassy.gov/pepfars/ pepfarstateskar.pdf].

14. Mysore District. [http://www.mysore.nic.in/index.htm].

15. National AIDS Control Organisation: National Behavioural Surveillance Survey (BSS) 2006. 2006 [http://www.nacoonline.org/upload/NACO\% 20PDF/General_Population.pdf].

16. Kausar R: Maternal Mortality in India - Magnitude, Causes and Concerns. Indian Journal for the Practising Doctor 2005, 2(2)

17. India: Urban Poverty Report 2009: Factsheet. [http://data.undp.org.in/ poverty_reduction/Factsheet_IUPR_09a.pdf].

18. Wanyu B, Diom E, Mitchell P, Tih PM, Meyer DJ: Birth attendants trained in "Prevention of Mother-To-Child HIV Transmission" provide care in rural Cameroon, Africa. Journal of midwifery \& women's health 2007, 52(4):334-341.

19. Satishchandra DM, Naik VA, Wantamutte AS, Mallapur MD: Impact of training of traditional birth attendants on the newborn care. Indian J Pediatr 2009, 76(1):33-36

20. Mathur HN, Sharma PN, Jain TP: The impact of training traditional birth attendants on the utilisation of maternal health services. J Epidemiol Community Health 1979, 33(2):142-144.

21. Bang AT, Bang RA, Baitule SB, Reddy MH, Deshmukh MD: Effect of homebased neonatal care and management of sepsis on neonatal mortality: field trial in rural India. Lancet 1999, 354(9194):1955-1961.

\section{Pre-publication history}

The pre-publication history for this paper can be accessed here: http://www.biomedcentral.com/1471-2458/10/570/prepub

doi:10.1186/1471-2458-10-570

Cite this article as: Madhivanan et al:: Traditional birth attendants lack basic information on HIV and safe delivery practices in rural Mysore, India. BMC Public Health 2010 10:570.

\section{Submit your next manuscript to BioMed Central and take full advantage of:}

- Convenient online submission

- Thorough peer review

- No space constraints or color figure charges

- Immediate publication on acceptance

- Inclusion in PubMed, CAS, Scopus and Google Scholar

- Research which is freely available for redistribution

Submit your manuscript at www.biomedcentral.com/submit
C) Biomed Central 